$\mathrm{p}=0.02$ ) were significantly more prevalent than in abstinent LT recipients (table 1).

Conclusion At our center, almost $1 / 4$ of recipients consumed alcohol early on post-LT, all with a low-risk pattern according to AUDIT score. Interestingly, alcohol consumption was more prevalent in non-ALD-related LT.

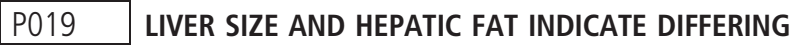 PHENOTYPES OF ACUTE ALCOHOLIC HEPATITIS}

${ }^{1}$ Nawaz Safdar*, 'Adam Tahir, ${ }^{2}$ Richard Parker. ${ }^{1}$ University of Leeds, Leeds, UK; ${ }^{2}$ St James's University Hospital, Leeds, UK

\subsection{6/gutjnl-2021-BASL.28}

Introduction Alcoholic hepatitis (AH) is an acute manifestation of alcohol related liver disease with very poor survival. The aim of this study was to identify phenotypes of $\mathrm{AH}$ based on radiological measures of liver size and hepatic fat content.

Methods Consecutive patients admitted to our institution with a clinical diagnosis of $\mathrm{AH}$ (based on the NIAAA definition) who had computed tomography (CT) imaging of the abdomen within 10 days of admission were included. $\mathrm{AH}$ phenotypes were defined by two parameters: a. hepatic steatosis was calculated using a liver/spleen attenuation ratio (LSR) of 1.0 as the cut-off, and b. liver volume characterised as small if $<2000 \mathrm{~cm} 3$ and large if $>2500 \mathrm{~cm} 3$. Hepatic VCAR was used to obtain both LSR and liver volumes. STATA 16 was used for statistical analyses. Kaplan Meier analysis was used to describe survival from admission and the log-rank test was used to compare survival between groups. Medians were used to describe biochemical data.

Results 47 patients were included, out of which $56.7 \%$ were male. The median patient age was 48 (range 25-76). Liver volumes varied considerably in this cohort (median $2589 \mathrm{~cm} 3$, range $1016 \mathrm{~cm} 3$ - $6352 \mathrm{~cm} 3)$. Patients were categorised as follows: Large Fatty (LF; $n=22)$, Large Non-Fatty (LNF; $n=4)$, Small Fatty $(S F ; n=15)$ and Small Non-Fatty (SNF; $n=6)$. Overall median survival was 427

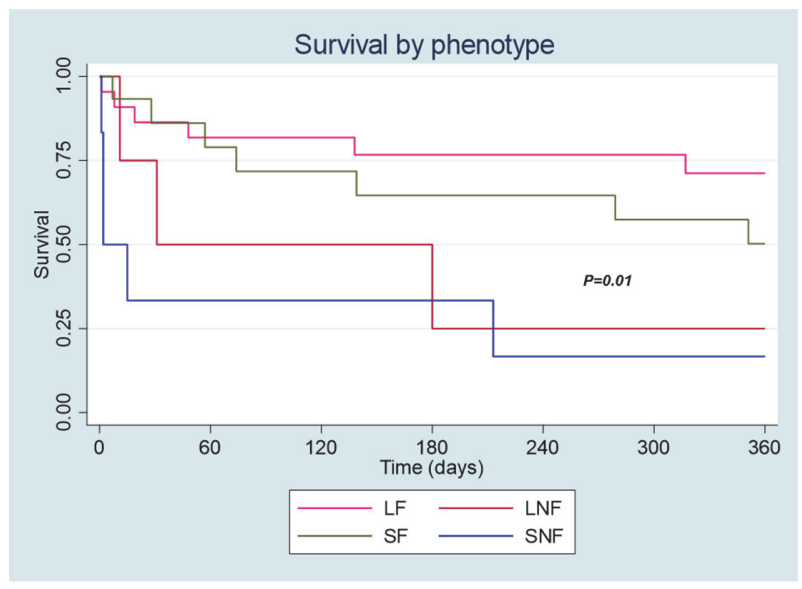

Abstract P019 Figure 1 days from admission. Survival was better in fatty livers compared to non-fatty livers $(\mathrm{P}=0.01$, figure 1$)$. These four groups differed with regard to median bilirubin and urea concentrations, which were both higher in patients with non-fatty livers (LF: bilirubin $=174.5 \mu \mathrm{mol} / \mathrm{L}$, ure$\mathrm{a}=3.25 \mathrm{mmol} / \mathrm{L} ; \mathrm{SF}$ : bilirubin $=74.5 \mu \mathrm{mol} / \mathrm{L}$, urea $=3.4 \mathrm{mmol} /$ $\mathrm{L}$; LNF: bilirubin $=250.5 \mu \mathrm{mol} / \mathrm{L}$, urea $=11.9 \mathrm{mmol} / \mathrm{L}$; SNF: bilirubin $=245.5 \mu \mathrm{mol} / \mathrm{L}$, urea $=7.1 \mathrm{mmol} / \mathrm{L}$ ). Only 3 patients were treated with corticosteroids, insufficient for analysis of treatment response.

Conclusion Liver volume varies significantly between patients admitted to hospital with acute AH. Patients with fatty livers have better medium-term survival and both lower bilirubin and urea levels than people with non-fatty livers.

\section{P020 IMPROVING CARE FOR PATIENTS WITH DELIRIUM TREMENS}

Clare Phillips*. University Hospital Southampton NHS Foundation Trust, Southampton, UK

\subsection{6/gutjil-2021-BASL.29}

Assess (the situation) From the start of 2021, as the UK entered another COVID19 lockdown, we noticed a stark increase in the numbers of patients presenting with, or developing, Delirium Tremens (DTs). While historically, it had been rare to see DTs within our organisation, it became a frequent occurrence and concerns were raised about staff safety and adverse outcomes for patients.

Diagnose (identify the problem) We (Alcohol Care Team) identified a knowledge gap in the recognition, treatment and nursing management of acute alcohol withdrawal amongst ward staff which was contributing to the onwards progression of DTs in patients.

Plan Using our Trust guidelines for alcohol withdrawal and team expertise, we developed a nursing care plan for patients experiencing acute alcohol withdrawal, outlining optimal care and highlighting key elements of the Trust policy.

Implement (deliver the plan) We used the care plan as a framework to guide informal teaching to staff on the Gastro/Hepatology wards. Furthermore, we made ourselves increasingly available when patients were in DTs and prioritised supporting staff in the hands on/active management of patients in DTs (akin to a low dose, high frequency approach, Jhpiego 2016) ${ }^{1}$ in order to maintain safety, optimise patient care and demonstrate clinical leadership.

Evaluate (did the plan work? Where are we now?) The care plan has been well received by staff. It is due to be submitted through our internal governance structure in order for it to be used as a clinical tool in practice.

\section{REFERENCE}

1. Jhpiego Resource Brief. Low dose, high frequency: a learning approach to improve health workforce competence, Confidence, and Performance [Internet]. Baltimore; 2016. Available from: www.healthynewbornnetwork.org/hnn-content/uploads/ Jhpiego-LDHF_briefer-1.pdf

Acknowledgments With thanks to all members of the Alcohol Care Team who peer reviewed the care plan. 


\section{Nursing care plan: Acute alcohol withdrawal}

\section{Alcohol withdrawal syndrome*}

Only occurs in patients who are alcohol dependent. Usually starts 8-24 hours after last consumption of alcohol/significant reduction.

Duration: Typically lasts 2-7 days. Peaks at 36-72 hours.

Clinical features: Nausea/vomiting, poor/no appetite, headache, tremor, tachycardia, palpitations, excessive sweating, hypertension, hyperreflexia (e.g., twitching, sensitivity to light or noise), insomnia, fatigue, restlessness, agitation, anxiety, and craving for alcohol. If untreated these symptoms can worsen progressing to hallucinations, seizures and delirium (see DTs). Assessed using: Clinical Institute Withdrawal Assessment for Alcohol revised (CIWA-Ar) - a clinical assessment tool.

Treated using: Benzodiazepines are the treatment for alcohol withdrawal. Benzodiazepines stabilise the neurotransmitters in the brain that become dysregulated following the cessation of alcohol.

*All information taken from UHS Alcohol Use Disorders: Guideline for Assessment and Management (April 2020) policy

\section{Delirium Tremens (DTs)*}

Begins 24-72 hours after last consumption of alcohol/significant reduction. High mortality rate (5-35\%) and is a medical emergency. We should consider delirium tremens a 'never' event, as it can be prevented. However, on occasion patients may present to hospital in DTs.

Clinical features: Differs from alcohol withdrawal in that there are signs of altered mental state e.g., hallucinations (visual/auditory/olfactory/tactile), confusion, delusions, severe agitation and seizures. Patients may not have the 'classic' signs of withdrawal e.g., tremor, sweats etc. Patients in DTs usually lack capacity to make decision about their care.

Treated using: Benzodiazepines (see Management of Delirium Tremens protocol ${ }^{*}$ for advice around use of haloperidol in these patients)

**Management of Delirium Tremens protocol can be found in Appendix C iv of the UHS trust policy - Alcohol Use Disorders: Guideline for Assessment and Management (April 2020) on StaffNet

Below is an example of a care plan for acute alcohol withdrawal. As with everything we do, each patient is an individual and the care plan may not cover every eventuality. Equally each problem identified on the care plan may not apply to your patient. Caring for patients in alcohol withdrawal requires critical thinking. Don't forget to use the nursing process (ADPIE) to guide the care you deliver:

Assess - gather information on the situation

Diagnose - what is the nursing diagnosis/problem identified?

Plan - what's your plan, goals, care you will implement?

Implement - deliver the care you have planned.

Evaluate - did your plan work? Where are we now?

\section{Any patient on this care plan/receiving benzodiazepines should be referred to the Alcohol Care Team - anyone can do this via Equest. If you have concerns about your patient or require support/advice please call 5721 or bleep 1808 (Mon-Fri 8am-8pm, Sat 9am-1pm)}

Care plan goal: To maintain patient safety and ensure safe withdrawal from alcohol

\begin{tabular}{|c|c|c|c|c|c|}
\hline \multirow{6}{*}{\begin{tabular}{|l|} 
Problem identified \\
1 . Monitoring signs \\
and symptoms of \\
alcohol withdrawal \\
and administering \\
benzodiazepines as \\
prescribed/required \\
\end{tabular}} & \multirow{6}{*}{$\begin{array}{l}\text { Background/rationale } \\
\text { At UHS we use the CIWA-Ar clinical assessment tool to } \\
\text { monitor/score alcohol withdrawal and to help guide } \\
\text { administration of regular and PRN doses of } \\
\text { benzodiazepines. } \\
\text { Benzodiazepines treat alcohol withdrawal, and it is } \\
\text { important these are administered in a timely manner. We } \\
\text { mainly use chlordiazepoxide unless the patient has } \\
\text { decompensated liver disease or is over } 80 \text { years old, when } \\
\text { we use oxazepam as it is shorter acting. If a patient is } \\
\text { NBM or declining tablets, IV/IM lorazepam/diazepam } \\
\text { may be used. } \\
\text { Most patients are prescribed a regular (gradually } \\
\text { reducing) regimen of benzodiazepines (5 or } 7 \text { day } \\
\text { course) with PRN doses available to be given as needed } \\
\text { in between. Patients can have up to } 250 m g \\
\text { chlordiazepoxide/oxazepam in a } 24 h r \text { period (if more } \\
\text { than this is needed, they need senior Dr review first). } \\
\text { Doses differ for lorazepam/diazepam. } \\
\text { Main complications of benzodiazepines } \\
\text { (chlordiazepoxide/oxazepam/lorazepam/diazepam) are } \\
\text { respiratory depression and drowsiness. Omit doses if the } \\
\text { patient is drowsy or there is evidence of respiratory } \\
\text { depression. }\end{array}$} & \multicolumn{4}{|c|}{ Nursing care/interventions planned } \\
\hline & & \multirow{3}{*}{$\begin{array}{l}\text { - Use CIWA-A } \\
\text { professiona } \\
\begin{array}{|l|}\text { Mild } \\
\text { withdrawal }\end{array}\end{array}$} & $\begin{array}{l}r \text { to score se } \\
\text { judgement }\end{array}$ & $\begin{array}{l}\text { erity of withdrawal - th } \\
\text { nd critical thinking skills }\end{array}$ & $\begin{array}{l}\text { able below can act as a guide, but } \\
\text { re crucial }\end{array}$ \\
\hline & & & $\begin{array}{l}\text { CIWA-Ar } \\
<10\end{array}$ & $\begin{array}{l}\text { Tense, irritable, poor } \\
\text { concentration. }\end{array}$ & $\begin{array}{l}\text { Repeat CIWA-Ar 2-4hrly } \\
\text { minimum. Administer regular } \\
\text { benzodiazepines (as } \\
\text { prescribed) unless drowsy. }\end{array}$ \\
\hline & & & $\begin{array}{l}\text { CIWA-Ar } \\
10-20\end{array}$ & $\begin{array}{l}\text { Tachycardia, nausea, } \\
\text { tremor, sweats, } \\
\text { anxious, headache, } \\
\text { irritable }\end{array}$ & $\begin{array}{l}\text { Give } 10-20 \mathrm{mg} \text { PRN or regular } \\
\text { dose if due, check effect after } \\
30 \text { mins, if improved repeat } \\
\text { CIWA-Ar 2-4hrly. If not } \\
\text { improving, give further } 10- \\
20 \mathrm{mg} \text { PRN (repeat steps } \\
\text { above) }\end{array}$ \\
\hline & & $\begin{array}{l}\text { Severe } \\
\text { withdrawal }\end{array}$ & $\begin{array}{l}\text { CIWA-Ar } \\
>20\end{array}$ & $\begin{array}{l}\text { Confusion, visual or } \\
\text { auditory } \\
\text { hallucinations, } \\
\text { irrational } \\
\text { thoughts/fears, } \\
\text { bizarre, aggressive or } \\
\text { uncooperative } \\
\text { behaviour, seizures }\end{array}$ & $\begin{array}{l}\text { Give 20-30mg } \\
\text { PRN/STAT/regular dose if } \\
\text { due, check effect after } \\
30 \text { mins, if improved repeat } \\
\text { CIWA-Ar hourly. If no } \\
\text { improvement give further } \\
\text { PRN (see Management of } \\
\text { Delirium Tremens protocol** } \\
\text { if concerned in DTs) }\end{array}$ \\
\hline & & \multicolumn{4}{|c|}{$\begin{array}{l}\text { - Administer regular benzodiazepines as prescribed } \\
\text { - Omit benzodiazepines if drowsy/respiratory depression } \\
\text { - Assess effect of PRN doses } 30 \text { minutes after administration using CIWA-Ar }\end{array}$} \\
\hline \multirow[t]{2}{*}{$\begin{array}{l}\text { 2. Haemodynamic } \\
\text { instability (NEWS) }\end{array}$} & $\begin{array}{l}\text { In acute alcohol withdrawal and DTs, common } \\
\text { abnormalities in observations include hyperthermia, } \\
\text { tachycardia, arrhythmias, hypoglycaemia, hypertension }\end{array}$ & \multicolumn{4}{|c|}{$\begin{array}{l}\text { - If stable and mild-moderate withdrawal - 4hrly observations. Escalate NEWS as per } \\
\text { trust policy. } \\
\text { - Severe withdrawal (CIWA-Ar >20) - hourly observations. Escalate NEWS as per trust } \\
\text { policy. }\end{array}$} \\
\hline & $\begin{array}{l}\text { Main complication of benzodiazepines } \\
\text { (chlordiazepoxide/oxazepam/lorazepam/diazepam) is } \\
\text { respiratory depression and drowsiness. Pupils may be } \\
\text { dilated. Flumazenil is the drug used to reverse } \\
\text { benzodiazepines in cases of overdose }\end{array}$ & \multicolumn{4}{|c|}{$\begin{array}{l}\text { - Moderate-severe withdrawal - } 2 \text { hrly blood glucose levels for first } 12 \mathrm{hrs} \text { of admission } \\
\text { - } \quad \text { If evidence of over-sedation (assess CNS with tool e.g., AVPU) or respiratory } \\
\text { compromise (reduced respiratory rate and/or low saturations) - omit } \\
\text { benzodiazepines (and other CNS depressants e.g., morphine) and inform medical } \\
\text { team/seek help }\end{array}$} \\
\hline
\end{tabular}




\begin{tabular}{|c|c|c|}
\hline $\begin{array}{l}\text { 3. Poor nutritional } \\
\text { intake }\end{array}$ & $\begin{array}{l}\text { People who drink alcohol dependently commonly report } \\
\text { poor diet/oral intake and may present to hospital in } \\
\text { refeeding syndrome and very malnourished. Diarrhoea } \\
\text { and vomiting are common and people who drink at } \\
\text { higher/dependent levels may also have gut } \\
\text { malabsorption. Specifically, high alcohol use is strongly } \\
\text { associated with thiamine (vitamin B1) deficiency. } \\
\text { Deranged electrolytes (due to refeeding syndrome and } \\
\text { high alcohol use) and thiamine deficiency are therefore } \\
\text { common in patients withdrawing from alcohol and may } \\
\text { contribute to confusion/agitation whilst also placing } \\
\text { patients at risk of other complications such as cardiac } \\
\text { arnthmias. }\end{array}$ & $\begin{array}{l}\text { - Dietician referral if concerns (as per usual trust policy) or if any indication of } \\
\text { refeeding syndrome (the medical team will be reviewing the need for this) } \\
\text { - Frequently prompt patient to eat - food chart if concerns } \\
\text { - Encourage oral fluids frequently } \\
\text { - Timely administration of IV/oral electrolyte replacement and IV Pabrinex/oral } \\
\text { vitamins as prescribed } \\
\text { - Patent cannula - ensure VIP score completed/cannula care as per trust policy } \\
\text { BGL monitoring (as per section 1) }\end{array}$ \\
\hline $\begin{array}{l}\text { 4. Maintaining a } \\
\text { safe environment }\end{array}$ & $\begin{array}{l}\text { Patients in withdrawal may become agitated, aggressive } \\
\text { or hallucinate. Patients will not be aware they are doing } \\
\text { this - this is not a patient 'behaving badly', they are } \\
\text { critically unwell. Patients may try to leave the ward. They } \\
\text { may not be safe to be left unsupervised. They may be } \\
\text { unsteady on their feet and at risk of falls. }\end{array}$ & $\begin{array}{l}\text { - Nurse in a calm, well-lit and well-ventilated environment - minimise noise and } \\
\text { activity where possible (also see section 5) } \\
\text { - Ensure nicotine replacement is offered/prescribed if applicable (patient may be } \\
\text { trying to leave to have a cigarette, nicotine replacement may reduce irritability) } \\
\text { - Can they be moved to a quieter side room or a bed visible from the nurse's station } \\
\text { (whichever is most appropriate)? } \\
\text { - Do they need to be under a DOLS? Are you concerned about their capacity to refuse } \\
\text { treatment or leave? Raise with medical team if so } \\
\text { - Request } 1: 1 \text { staffing, } 2: 1 \text { staffing may even be required at times, staff safety is } \\
\text { paramount. Discuss with bleep holder/matron. Please see the Enhanced Care } \\
\text { Observation Policy (Sept 2020) on StaffNet (formerly called the specialling policy) for } \\
\text { further guidance if close observation is indicated. } \\
\text { - Falls prevention care (as per trust policy) - ensure they have appropriate footwear on, } \\
\text { keep bedspace clear of trip hazards, ensure walking aids are to hand if used etc. }\end{array}$ \\
\hline $\begin{array}{l}\text { 5. Impaired } \\
\text { communication }\end{array}$ & $\begin{array}{l}\text { Patients are often anxious, agitated and/or may be } \\
\text { hallucinating. They may not be able to express their } \\
\text { concerns and may not understand what is happening } \\
\text { around them. Withdrawal from alcohol can be really } \\
\text { frightening. Reassurance and good communication skills } \\
\text { are vital. } \\
\text { Of note, people in alcohol withdrawal/DTs may speak } \\
\text { their first language if English is a second language (even } \\
\text { if they usually speak English well). }\end{array}$ & $\begin{array}{l}\text { - If English not spoken/understood - can we use language line? Can they be cared for } \\
\text { by a member of staff who speaks their language? } \\
\text { - Ensure baseline communication aids are working and being used (e.g., hearing aids) } \\
\text { - Try to create a calm environment by using lower tone/volume of voice, avoid } \\
\text { confrontation/grabbing/restraining (unless there is an immediate risk of serious } \\
\text { injury/harm to patient or others in which case reasonable and proportionate force } \\
\text { can be used), make instructions clear and minimal, keep the environment quiet as far } \\
\text { as you can } \\
\text { - Reassure patient regularly, do not challenge delusions but gently reorientate them to } \\
\text { where they are and what is happening } \\
\text { - Ensure family are involved in care - via phone or visits (as permitted) }\end{array}$ \\
\hline $\begin{array}{l}\text { 6. Assistance with } \\
\text { personal care }\end{array}$ & $\begin{array}{l}\text { People in alcohol withdrawal may be unable to meet } \\
\text { their own self-care needs/activities of daily living } \\
\text { temporarily. }\end{array}$ & $\begin{array}{l}\text { - Assist with washing and dressing as required } \\
\text { - Prompt to use the toilet regularly - provide care if incontinent } \\
\text { - Frequent bed/clothes changes - profuse sweating is common in alcohol withdrawal } \\
\text { - Consider pressure area care }\end{array}$ \\
\hline $\begin{array}{l}\text { 7. Emergency } \\
\text { preparedness }\end{array}$ & $\begin{array}{l}\text { Delirium tremens, seizures and cardiac arrest are } \\
\text { complications of withdrawal that we aim to avoid by } \\
\text { providing the care in the plan above. } \\
\text { However, in rare situations these may occur. It is } \\
\text { important to be prepared for this and to know what to } \\
\text { do should they arise. }\end{array}$ & $\begin{array}{l}\text { - Check bedside safety equipment at the start of each shift- do you have working } \\
\text { suction at the bedside? Is there a non-rebreathe mask available and a nipple on the } \\
\text { bedside oxygen? } \\
\text { - Do you know where the crash trolley is? } \\
\text { - Do you know the emergency numbers for the crash team in case of seizure/cardiac } \\
\text { arrest (2222) and security if the patient is aggressive or tries to leave (and is under } \\
\text { DOLS)? (3333) } \\
\text { - Notify the medical team and Alcohol Care Team if you are struggling to manage the } \\
\text { patient's withdrawal (remember to evaluate the care you are giving throughout the } \\
\text { shift - is it working? Get help if it isn't) } \\
\text { - Be familiar with the Management of Delirium Tremens protocol**. Think ahead - if } \\
\text { you are worried your patient is moving in this direction have this to hand, ensure the } \\
\text { necessary drugs have been prescribed and medical and alcohol teams are aware. } \\
\text { - The alcohol nurses are happy to come and help stabilise patients in withdrawal } \\
\text { (bleep 1808. Ext 5721) }\end{array}$ \\
\hline
\end{tabular}

Abstract P020 Figure 1 Nursing care plan: acute alcohol withdrawal (attached)

\section{P021 REVIEW OF IMPACT OF COVID 19 ON HEPATOCELLULAR CARCINOMAS (HCCS) PRESENTED AT THE NORTHERN IRELAND (NI) REGIONAL MDM}

Rebecca O' Kane*, Neil McDougall. Royal Victoria Hospital, UK

\subsection{6/gutjnl-2021-BASL.30}

Introduction The COVID 19 pandemic has impacted the management of most patients including those with chronic liver disease. HCC usually arises in patients with liver cirrhosis and the Belfast Trust HCC screening program was suspended for 3 months in 2020.
Our aim was to assess the number and source of referrals along with treatment outcomes for 2020 compared to 2019. Methods The regional HPB MDM database was reviewed to identify all HCC cases during a 12 month period from 1st January 2020. Results were compared with an audit of HPB MDM outcomes from 2019.

Results 80 patients with HCC were identified, compared to 82 in 2019. There was a reduction in referrals as expected in the second quarter of 2020 , as illustrated in the table 1 .

$12(15 \%)$ patients were detected via HCC screening programme, compared to $19(23 \%)$ in 2019. 